LBNL- 53908

\author{
Association of Airborne Moisture-Indicating Microorganisms \\ with Building-Related Symptoms and Water Damage \\ in 100 U.S. Office Buildings: \\ Analyses of the U.S. EPA BASE Data
}

Mark J. Mendell, Quanhong Lei, Myrna Cozen, Derek G. Shendell

\author{
Indoor Environment Department \\ Environmental Energy Technologies Division \\ Lawrence Berkeley National Laboratory \\ Berkeley, CA 94720 \\ Janet M. Macher, Feng C. Tsai, Derek G. Shendell \\ Indoor Air Quality Section \\ Environmental Health Laboratory Branch \\ California Department of Health Services \\ Richmond, CA 94804
}

This work was supported by the Indoor Environments Division, Office of Radiation and Indoor Air, Office of Air and Radiation of the U.S. Environmental Protection Agency through interagency agreement DW89939365-01-0 with the U.S. Department of Energy and Requisition No PR-DC-01-00105/BB3223, BASE Analysis, Contract Number 1W-2348NANX with the California Department of Health Services. This work was also supported by the assistant Secretary for Energy Efficiency and Renewable Energy, Building Technologies Program of the U.S. Department of Energy under contract DE-AC0376SF00098 Requisition/Purchase Req. No PR-DC-01-00105/BB3223, BASE Analysis, Contract Number 1W-2348-NANX with the U.S. Environmental Protection Agency. 


\title{
Association of Airborne Moisture-Indicating Microorganisms with Building-Related Symptoms and Water Damage in 100 U.S. Office Buildings: Analyses of the U.S. EPA BASE Data
}

\author{
Mark J. Mendell \\ Quanhong Lei \\ Janet M. Macher \\ Myrna Cozen \\ Feng C. Tsai \\ Derek G. Shendell
}

\begin{abstract}
Background: Metrics of culturable airborne microorganisms for either total organisms or suspected harmful subgroups have generally not been associated with symptoms among building occupants. However, the visible presence of moisture damage or mold in residences and other buildings has consistently been associated with respiratory symptoms and other health effects. This relationship is presumably caused by adverse but uncharacterized exposures to moisturerelated microbiological growth. In order to assess this hypothesis, we studied relationships in U.S. office buildings between the prevalence of respiratory and irritant symptoms, the concentrations of airborne microorganisms that require moist surfaces on which to grow, and the presence of visible water damage.

Methods: For these analyses we used data on buildings, indoor environments, and occupants collected from a representative sample of 100 U.S. office buildings in the U.S. Environmental Protection Agency's Building Assessment Survey and Evaluation (EPA BASE) study. We created 19 alternate metrics, using scales ranging from 3-10 units, that summarized the concentrations of airborne moisture-indicating microorganisms (AMIMOs) as indicators of moisture in buildings. Two were constructed to resemble a metric previously reported to be associated with lung function changes in building occupants; the others were based on another metric from the same group of Finnish researchers, concentration cutpoints from other studies, and professional judgment. We assessed three types of associations: between AMIMO metrics and symptoms in office workers, between evidence of water damage and symptoms, and between water damage and AMIMO metrics. We estimated (as odds ratios (ORs) with 95\% confidence intervals) the unadjusted and adjusted associations between the 19 metrics and two types of weekly, work-related symptoms - lower respiratory and mucous membrane - using logistic regression models. Analyses used the original AMIMO metrics and were repeated with simplified dichotomized metrics. The multivariate models adjusted for other potential confounding variables associated with respondents, occupied spaces, buildings, or ventilation systems. Models excluded covariates for moisture-related risks hypothesized to increase
\end{abstract}


AMIMO levels. We also estimated the association of water damage (using variables for specific locations in the study space or building, or summary variables) with the two symptom outcomes. Finally, using selected AMIMO metrics as outcomes, we constructed logistic regression models with observations at the building level to estimate unadjusted and adjusted associations of evident water damage with AMIMO metrics.

Results: All original AMIMO metrics showed little overall pattern of unadjusted or adjusted association with either symptom outcome. The 3-category metric resembling that previously used by others, which of all constructed metrics had the largest number of buildings in its top category, was not associated with symptoms in these buildings. However, most metrics with few buildings in their highest category showed increased risk for both symptoms in that category, especially metrics using cutpoints of $>100$ but $<500$ colony-forming units $(\mathrm{CFU}) / \mathrm{m}^{3}$ for concentration of total culturable fungi. With AMIMO metrics dichotomized to compare the highest category with all lower categories combined, four metrics had unadjusted ORs between 1.4 and 1.6 for both symptom outcomes. The same four metrics had adjusted ORs of 1.7-2.1 for both symptom outcomes. In models of water damage and symptoms, several specific locations of past water damage had significant associations with outcomes, with ORs ranging from 1.41.6. In bivariate models of water damage and selected AMIMO metrics, a number of specific types of water damage and several summary variables for water damage were very strongly associated with AMIMO metrics (significant ORs ranging above 15). Multivariate modeling with the dichotomous AMIMO metrics was not possible due to limited numbers of observations.

Discussion: This analysis identified metrics of airborne moisture-indicating microorganisms that, at their highest levels in these representative office buildings, were associated with increased lower respiratory and mucous membrane symptoms among occupants. These metrics were also much more strongly associated with evidence of specific types of water damage. This finding provides some evidence that the presence of airborne moisture-requiring organisms signals the presence of water damage and of indoor conditions with adverse health effects, but may also indicate that only in a minority of typical buildings are levels of moisture sufficiently high to substantially influence respiratory and irritant symptoms. The two symptom outcomes were more strongly associated with several dichotomous AMIMO metrics than with any variables for evident water damage. More quantitative summaries of water damage not possible using the EPA BASE data may better predict symptoms. As the AMIMO metrics in final analyses here were chosen and revised based on associations in the data with symptoms, these findings need replication. Ultimately, more refined AMIMO metrics, possibly in conjunction with metrics for visible water damage or measured moisture, may predict health risks from water damage in buildings. Until the elusive causal exposures underlying the associations between moisture and health effects are identified, metrics for AMIMOs and visible water damage may provide the best available tools to study water damage and microbial growth in buildings. 


\section{Background}

Investigations of reported building-related symptoms (BRS) in office buildings have often identified microbiologic growth or water damage, either visible or hidden, in the buildings. Nevertheless, researchers have not consistently found associations in offices or other work environments between symptoms and airborne microorganisms measured with conventional methods. In contrast, simpler, indirect metrics based on visible moisture and mold have been consistently associated with respiratory or other health effects, in many studies, mostly in residences but some in non-residential environments (Bornehag et al. 2001). This suggests that, while excess moisture in buildings may lead to adverse exposures, current methods have not successfully both targeted and quantified the specific microbiologic exposures which cause human health effects. Until specific causal agents for moisture-related health effects in buildings are identified, only indirect indicators of these exposures will be available to use for prevention and remediation. Moisture in buildings has been a successful indicator; however, usually assessed crudely, it is difficult to quantify, especially since important moisture may not be visible. This analysis compares two types of potential indicators of moisture, using existing data.

A recent study in Finland used a new index for water damage (Seuri et al. 2000). The novel index was based, not on inspection, but on the presence of specific culturable airborne microorganisms that only grow indoors when sufficient moisture is available. The study evaluated a set of buildings, half of which were chosen because of serious water damge, using the index of airborne microorganisms presumed to indicate the presence of wet materials on which the organisms were growing. This index was significantly associated with an objectively measured adverse respiratory health effect - increased variability in peak expiratory flow.

This index was an indirect indicator of elevated indoor moisture, and thus of any resulting exposure to airborne bacterial or fungal cells or volatile or particulate microbial products, measured or unmeasured. That the index should be associated with an objectively measured adverse respiratory effect suggests that the moisture damage with which these organisms are associated in turn is associated with irritant, allergenic, or toxic exposures of a kind not captured in the usual microbiologic metrics. This finding is in a way analogous to that of Ten Brinke (1998): although an index directly estimating the irritancy of volatile organic compounds (VOCs) found in the air in a set of office buildings was not associated with symptoms in occupants, several statistically correlated clusters of VOCs, thus identified as occurring together in buildings, were associated with irritant symptoms. Ten Brinke suggested that each cluster of VOCs found to occur together might indicate a common source for that group of VOCs and, therefore, might correlate with both measured and unmeasured emissions from the source, some of which may have caused the irritant symptoms. While construction of the microbiologic index of moisture was based on prior knowledge, and the VOC clusters of Ten Brinke at al. were based on statistical correlation, the novel application of both metrics to indicate other unmeasured contaminants is similar. 
An index of airborne moisture-indicating microorganisms (AMIMOs), if confirmed as a predictor of adverse health effects, should provide a more objective measure of moisture damage and related health risk than visible evaluation of moisture, even if the specific causal exposures for health effects have not yet been identified. As an indicator it may also ultimately help identify the causal exposures.

The U.S. Environmental Protection Agency's Building Assessment Survey and Evaluation (EPA BASE) study, which collected data from a representative set of office buildings located throughout the U.S., has provided the data needed to calculate such indices of moistureindicating organisms, information on visible moisture damage, and data on symptoms among occupants. This has created an opportunity to assess the relationships among these factors. Prior analyses of these data have identified several kinds of risk factors for increased symptoms among occupants of the BASE buildings, including lower ventilation rates, but have not assessed factors related to water damage (Apte and Daisey 1999; Apte et al. 2000; Erdmann et al. 2002).

The objectives of this analysis were to assess (1) whether an index of AMIMOs in office buildings is associated with risk of respiratory and other symptoms among U.S. office workers, (2) whether water damage evident from building inspections is associated with these symptoms, and (3) whether an AMIMO index is correlated with water damage evident from inspection.

\section{Methods}

In brief, this analysis involved three parts, explained in detail below. After constructing alternate AMIMO indices from the EPA BASE data, we assessed relationships between these indices and respiratory and irritant symptoms using multivariate statistical models. Based on these findings, we simplified the metrics and repeated the modeling. We also estimated multivariate-adjusted associations between reported or visually-detected water damage in the buildings and the symptom outcomes. Finally, we used the simplified AMIMO metrics as outcome variables in models that assessed associations between AMIMO metrics and evident water damage.

\section{EPA BASE data}

We used the EPA BASE data set, collected between 1994-1998 by the U.S. EPA from 100 U.S. office buildings, which includes a variety of information on both occupants and buildings. Descriptions of this study and the available data have been reported previously (Womble et al. 1996; Brightman et al. 1999; Womble et al. 1999). Briefly, the study selected a representative set of 100 office buildings from geographic regions throughout the U.S., and then randomly selected within each building one study space with at least 50 occupants, with no more than two air handling (ventilation) units, and on no more than 3 floors. Three sites within the space were selected randomly for environmental measurements (Womble et al. 1996). Data were collected from questionnaires given to all occupants working on Wednesday and Thursday of the chosen study week in each study space. Data also were collected from standardized inspections of the buildings and ventilation systems, interviews conducted with facility managers, and environmental monitoring in the buildings. Each building was studied once in either summer or winter. 
Our analyses used two symptom-based health outcome definitions: lower respiratory symptoms (at least one of wheezing, shortness of breath, chest tightness, and cough) and mucous membrane symptoms (one or more of dry or itchy eyes, stuffy or runny nose, and sore or dry throat). Analyses were of "weekly, work-related" symptom outcomes, defined as those experienced at least once per week within the last four weeks while at work and also improving outside of the building.

Independent variables included information from the self-completed occupant questionnaires (on demographic, health status, job, and workspace factors) and information collected by study personnel: inspection of ventilation systems, buildings, and occupied spaces; interviews with facility managers on building- and ventilation system-related practices and history; and measurements of environmental parameters such as temperature, relative humidity, and ventilation rate as well as culturable airborne bacteria and fungi. We selected data variables pertinent to our hypotheses and modified and combined them as needed for the present analyses. The two types of primary risk variables in this analysis were alternate metrics for AMIMOs, and variables for water damage in the study spaces or buildings.

\section{AMIMO metrics}

The list of bacteria and fungi used for calculating AMIMO concentrations in each EPA BASE building was based, as was that of Seuri et al. (2000) in Finland, on recommendations from an international workshop of microbiologists (Samson et al. 1994). The bacteria and fungi on the original list were proposed as "indicator" microorganisms for buildings with either moisture or health problems if the concentrations of these microorganisms exceeded a baseline level (not yet established) in either air or surface samples (Samson et al. 1994). The Finnish group used the list as a list of moisture-indicating microorganisms to study associations between building dampness and health effects. With this same objective, we created 19 AMIMO classification "metrics," with scale widths ranging from 3-10 units (Macher et al. 2003). The metrics used air concentrations of culturable microorganisms included in the list of Samson et al., which required different, but mostly high, levels of water activity on or in materials for growth. All of the bacterial groups on the original list were identified in EPA BASE buildings: actinomycetes and Gram-negative bacteria. Only eight of the original twelve fungal groups were reported during the BASE study: Aspergillus fumigatus, Aspergillus versicolor, species of Fusarium, Penicillium, Trichoderma, Ulocladium, and Wallemia, and yeasts. Stachybotrys fungi were not detected in the primary indoor samples used for these analyses, but were reported in some duplicate samples.

Each metric combined the multiple indoor air samples for culturable bacteria and fungi into a single numeric index for each BASE building. The first index replicated, to the extent possible given the differences in study protocols, the metric of Seuri (2000). The other indices were based on another metric from the same group of Finnish researchers, concentration cutpoints from other studies, and professional judgment. 
The EPA BASE microbiologic sampling protocol specified three sampling sites within the study space in each BASE building. At each sampling site, four air samples were to be collected (2and 5-minute samples in the morning and afternoon) for each of three microbial groups culturable fungi, mesophilic bacteria, and thermophilic bacteria. To apply Seuri's criteria, we calculated three composite mean AMIMO concentrations (one per sampling site) for each of the 100 BASE buildings, using primary samples only and the following formulae:

mean AMIMO concentration

$$
=\{(3 \text { (mean AMIMO bacteria concentration })+8(\text { mean AMIMO fungi }
$$
concentration) $\} / 11$,

where mean AMIMO bacteria concentration (3 groups)

$=(\Sigma$ Actinomycetes + Bacillus + Gram-negative cocci + Gram-negative rods $) /$ (number of observations),

and mean AMIMO fungi concentration (8 groups)

$=(\Sigma$ Aspergillus fumigatus + Aspergillus versicolor + Fusarium spp.+ Penicillium spp. + Trichoderma spp. + Ulocladium spp. + Wallemia spp. + Yeasts) / (number of observations).

For Metric 1, we generated a 3-category building index directly from three site-averaged AMIMO concentrations. For Metrics 2-19, we generated a separate three- or four-category "site score" for each of the three indoor sampling sites and summed the site scores for the building index (7- or 10-category building indices). For Metrics 3-10, we developed 4-category scoring systems based on building-wide average and site-specific concentration distributions of AMIMOs and total fungi. Metrics 6-19 represent seven pairs of metrics, with each pair consisting of a ten-category and a four-category metric otherwise based on a single algorithm. The seven algorithms used increasing cutpoints for scoring the concentration of total culturable fungi: 48, 90, 100, 150, 170, 200, and $500 \mathrm{CFU} / \mathrm{m}^{3}$. The bold values are the $50^{\text {th }}, 75^{\text {th }}$, and $90^{\text {th }}$ percentiles of the BASE distribution, the other cutpoints are rounded values, and the highest cutpoint was taken from guidance literature.

Appendix 1 provides, for each of the 19 AMIMO metrics, the algorithm for construction and the scores for each building. The use of building-wide distributions in some algorithms reduced the effects of extremely high concentrations at individual sites. The site-specific distributions (i.e., separate distributions for the three sampling sites within each building) used, on the other hand, preserved the influence of extreme concentrations within a series of site scores. We generated indices using alternate combinations of the two distributions for both microbial groups because it is not known which is a better predictor of occupant symptoms when occupants cannot be linked with indoor sampling sites. See the complete report for details (Macher et al. 2003).

\section{Summary variables for water damage}

The EPA BASE study collected data, by observation and interview, regarding a large number of conditions and features in the study buildings. The available data include the presence or absence of water damage, past or current, in the occupied spaces, mechanical rooms, basement, 
roof, or other locations in the building, with similar data collected both at the building and study space levels. Without information on the extent or severity of water damage, these data were not sufficient to produce a quantitative index of water damage such as used by Seuri et al. (2000). We therefore used three kinds of variables to indicate water damage: 11 available variables for water damage in specific locations (e.g., in the study spaces, roofs, basements, and mechanical rooms); four summary variables (any past, and any current, water damage in the study space; any past, and any current, water damage in the building); and two more concise summary variables (any past, and any current, water damage).

\section{Statistical modeling - AMIMO metrics and symptoms}

Data analysis and statistical modeling were performed using SAS version 8.2 (SAS Institute Inc. 2002). The overall process of selecting and reducing variables for analysis is described in more detail elsewhere (Mendell et al. 2003).

We first estimated unadjusted associations of each of the 19 metrics with the two types of weekly, work-related symptoms - lower respiratory and mucous membrane - using logistic regression models with observations at the respondent level. The models used categorical variables to allow estimation of risk for each level of each metric as an odds ratio (OR) with $95 \%$ confidence intervals.

Based on the patterns of risk in the resulting estimates, we collapsed categories as appropriate, consistently across all metrics, to create dichotomized AMIMO metrics. We then constructed multivariate logistic regression models to assess unadjusted and adjusted associations between the dichotomized AMIMO metrics as primary risks and the two types of symptoms. Construction of final multivariate models involved first constructing and reducing several subgroup models of large numbers of potential confounding covariates and then entering the remaining covariates from each, with the primary risks, into an initial full model. Initial models included personal variables related to demographic, health, and job factors, and environmental variables related to occupied spaces, buildings, or ventilation systems. Models also included variables based on environmental monitoring data: temperature (average number of hours*degrees per day that the indoor temperature was above $20^{\circ} \mathrm{C}$ ) [Apte, $2000 \# 461$ ], relative humidity (RH, mean indoor RH on one day), mean indoor minus outdoor concentration of carbon dioxide for each building (as a surrogate for ventilation rate). Models excluded covariates for building- or HVAC-related risk factors for moisture (HVAC condition and maintenance, HVAC design and materials, and study space cleaning), which were hypothesized to increase AMIMO levels. Footnote 1 in Table 2 lists covariates potentially included in each model. We reduced each initial full model by sequentially removing covariates that did not contribute to models and also did not confound relationships of the primary risk factors to the outcomes. 


\section{Statistical modeling - water damage and symptoms}

We also estimated in respondent-level models the multivariate association with the two symptom outcomes of specific variables for water damage, of four summary variables for water damage, and of two overall summary variables for water damage. For each outcome, we constructed two kinds of models: all specific water damage variables together, and the four summary water damage variables together. We first constructed subgroup models for each outcome containing each full set of water damage variables as risks and sequentially eliminated risk variables not contributing to the models $(p>0.25)$. For each model we then added the same set of potential confounding variables as in the AMIMO/symptom models, with the addition of covariates related to HVAC condition and maintenance, HVAC design and materials, and study space cleaning (see Table 4, footnote 1) and reduced these initial full models in the same way.

\section{Statistical modeling - water damage and AMIMO metrics}

To select the AMIMO metrics that were most strongly associated with symptoms, we constructed a new set of logistic regression models with building-level observations $(\mathrm{n}=100)$, using the AMIMO metrics as the outcome variable. We used these models to estimate the unadjusted and adjusted associations with AMIMO metrics of the three kinds of variables for water damage: for specific locations, the four summary variables, and the two overall summary variables.

\section{Results}

Of the 19 AMIMO metrics constructed, 1 metric had 3 categories, 7 had 4 categories, 1 had 7 categories, and 10 had 10 categories (Table 1). No metric showed monotonic increases in unadjusted risk, for either symptom outcome, as metric scores increased (Table 1). Some tencategory metrics fluctuated substantially, particularly for the relatively rare lower respiratory symptom outcome, with values in some middle categories very high for metrics 3,4 , and 6 , and very low for metrics 8 and 10. For six of the nineteen metrics, however, the highest single AMIMO category had generally higher risks for at least one symptom than most other categories, which fluctuated without evident pattern. This configuration was most common in the 10-category metrics. Results were similar for the two symptom outcomes assessed.

In the adjusted estimates for both outcomes (Table 2), risks found at the highest levels of some 10 -category metrics increased further, becoming statistically significant for metrics $10,12,14$, and 16, for one or both outcomes. Adjusted OR's were greater than or equal to 1.3 for both symptom outcomes with metrics 10,12,14, and 16 and for one symptom outcome with metrics 6 and 19. As with unadjusted estimates, increased ORs were more common among the 10category metrics. Fluctuations in middle category values decreased substantially in number and magnitude; e.g., the highest of these values was 1.3 instead of 1.8. Metric 1 (3 categories), constructed to resemble the metric used by Seuri et al. (2000), showed no relationship with increase in either symptom outcome, with even a tendency toward an inverse relationship with lower respiratory symptoms. 
For simplicity, we collapsed categories for each metric to create 19 dichotomous variables comparing the single highest category to a combination of the other $(2,3,6$, or 9$)$ categories. Table 3 shows the estimated associations between the dichotomous AMIMO metrics and the two symptom outcomes, as unadjusted and adjusted ORs from multivariate logistic regression models. Table 3 orders the AMIMO metrics by decreasing numbers of buildings in their higher category (i.e., their original highest category before being dichotomized). Four metrics (\#10, 12, 14,16 ) had unadjusted ORs between 1.4 and 1.6 for both symptom outcomes ( 3 of 8 ORs statistically significant), and the same four metrics had adjusted ORs of 1.7-2.1 for both symptom outcomes ( 5 of 8 statistically significant). These metrics had 3-4 buildings in their higher category. Five other metrics (\#17, 19, 5, 6, and 8) had adjusted ORs between 1.1 and 1.3 for at least one symptom outcome, but none as high as 1.4 , and none statistically significant. These metrics had 5-8 buildings in their higher category. Other metrics had adjusted ORs ranging from 0.8-1.0 for the two symptom outcomes. The magnitude of adjusted ORs were consistently and inversely related to the number of buildings in the higher category, except for metric \#18 with only one building in this category (Table 3 ).

Table 4 presents multivariate adjusted ORs for associations with the two symptom outcomes of the 11 specific water damage variables, and of the four summary water damage variables, after exclusion of water damage variables that did not contribute in initial models. The most elevated estimates for lower respiratory symptoms were for past water damage in the basement $(\mathrm{OR}=1.6)$, and the highest estimates for mucous membrane symptoms were for past water damage in any mechanical room (1.4) and in the study space (1.3). Other elevated ORs had broad confidence intervals. ORs for the four summary water damage variables showed little or no elevation, with none statistically significant; the largest OR was between any past water damage in the building $(\mathrm{OR}=1.3)$ and mucous membrane symptoms. The two overall summary variables for water damage were not associated with the symptom outcomes (not shown).

Table 5 shows the unadjusted associations from logistic regression models between selected AMIMO metrics as outcomes and water damage variables, only for associations with p-values $\leq 0.25$, with building-level observations. For some groups of metrics (e.g., 12, 14, 16; and 6,8) the same sets of buildings were in the high category of the metric; their identical estimates are shown together in Table 5. Past fire damage in the building was considered likely evidence of past water damage. For the specific water damage variables, ORs were very large (between 4 and 17) and some were statistically significant, although for many of these variables the confidence intervals were broad (models had at most 100 observations). Among the set of four summary water damage variables, the variable for any past damage in the building had no associations with the selected metrics. The ORs for the three of these summary variables with associations, although high (ranging from about 3-9), were not as high as the ORs for the specific water damage variables. The two overall summary water damage variables had no clear associations with the AMIMO metrics. AMIMO metric \#18 had no evident associations with any water damage variable. Other than for $\# 18$, ORs generally diminished as the number of buildings in the higher category of a dichotomized metric increased. 
Multivariate modeling for these relationships was not feasible, as models would not converge with only 4-8 positive outcomes out of 100 total observations.

\section{Discussion}

This paper reports an exploratory analysis of AMIMO metrics, representing 19 alternate ways to quantify the air concentrations of microorganisms known to require moist materials for growth and reproduction. The one 3-category metric previously reported to be associated with respiratory health effects had no association with symptoms in this analysis. Several other metrics based on the same general strategy, however, when dichotomized to distinguish their highest levels only, were associated with increased lower respiratory and mucous membrane symptoms among occupants. These dichotomized metrics were also strongly associated with past or current water damage in various building locations, with significant ORs ranging above 15.0, suggesting that water damage does influence the air concentrations of the organisms in the AMIMO metrics. Overall, these findings seem to provide clear evidence that the presence of moisture-requiring organisms signals a history of water damage, and some evidence that this indicates conditions with risks of increased symptoms.

The findings also indicated that only in a minority $(<10 \%)$ of these "normal" or representative buildings were levels of moisture sufficiently high to have apparent influence on the symptoms assessed here. As the AMIMO metrics in final analyses here were chosen and revised based on associations with symptoms in the data (although not based on associations with water damage), these findings need replication in other buildings.

The highest ORs for associations between different AMIMO metrics and the two symptom outcomes (significant ORs from 1.8-2.1) were slightly higher than the highest ORs for association between types of visible water damage and the symptoms (significant ORs from 1.51.8). This analysis did not assess the simultaneous associations of AMIMO metrics and water damage variables with symptom outcomes, to see how much independent information each provides.

In these data, the more classification categories in an AMIMO metric, the more generally likely that the highest category would have an elevated OR for both symptom outcomes (Table 3). Yet the number of buildings in the highest category of each metric, determined by a combination of the number of categories and the stringency of criteria for classification, seemed even more strongly (inversely) related to the strength of association with both symptoms than the underlying number of categories. This relationship was consistent except for metric \#18, with only 1 building in its highest category (Table 3). This finding is consistent with the possibility that, within the range of moisture-indicating organisms found in normal U.S. office buildings, a threshold of additional risk is associated only with the highest level, occurring in this sample in only $3-4 \%$ of the buildings. In a set of buildings in which water damage is evident or occupants have environmentally-related health complaints, perhaps this proportion would be higher, as it 
was in the Finnish study in which half the buildings had known moisture problems and complaints (Seuri et al. 2000). The role of the concentration cutpoint used in scoring each metric (e.g., metric 18 used the highest cutpoint) may be important and needs further exploration.

Both current and past water damage, in either the occupied space or other building locations such as basement, mechanical room, or occupied space, were associated strongly with the AMIMO metrics. Also, a history of fire damage in the building, presumably an indicator of water damage as well, was among the variables most strongly associated with the AMIMO metrics, with ORs up to 17.4. (Although numerous associations were assessed, more significantly elevated ORs occurred than would by chance alone - approximately two per AMIMO metric compared to less than one expected by chance.) In contrast, among variables for water damage, only past water damage at various building locations outside the study space was significantly associated with occupant symptoms (and with only about the number of associations expected by chance), although there were nonsignificantly elevated ORs for some variables for past and current water damage in occupied spaces. An example of this discrepancy is that the statistically significant OR for past fire damage and the identical dichotomous AMIMO metrics 12, 14, and 16 was 17.4 (Table 5), yet the ORs for past fire damage and both symptom outcomes were 1.0 (Table 4). If water damage at many locations, either current or past, in fact influences AMIMO concentrations, but only water damage at a few key locations in the past is clearly associated with health, it would suggest that the AMIMO metric is indicative of moisture more generally than for moisture leading to harmful exposures more specifically. Either association would be theoretically plausible, as the AMIMO metrics were constructed from a list of bacteria and fungi proposed as "indicator" organisms in buildings with either moisture or health problems if concentrations exceeded an unknown baseline level in either air or surface samples (Samson et al. 1994).

\section{Comparison to findings of others}

Prior analyses of the BASE data have shown associations between lower ventilation rates in the BASE buildings (although not low by current ventilation standards) and increases in several building-related symptoms, both in a 40-building subset (Apte and Daisey 1999) and in the full set of 100 buildings (Erdmann et al. 2002). These prior findings tend to corroborate the presence in indoor air in the BASE buildings of contaminants, removable by ventilation, but still uncharacterized, that cause building-related symptoms. Water damage is a plausible potential source for indoor microbiologic contamination.

While associations between observed water damage or mold and adverse respiratory health effects have been consistently reported in residences (Bornehag et al. 2001; Haverinen et al. 2001), less research has been reported for such associations in adult workers in buildings such as offices.

Seuri et al. [, $2000 \# 334]$ used an index of moisture-indicating microorganisms in a study of offices and other buildings in Finland. These researchers studied 11 buildings with severe signs of moisture damage and mold and 11 matched reference buildings. Two different classification 
schemes (a two-category and a three-category scheme) were used, based on visible signs of moisture and mold found by inspection of the buildings, along with a third scheme (with threecategories) based on measured concentrations of airborne microorganisms considered to indicate water damage. The list of qualifying organisms was based on the recommendations of an international group of microbiologists (Samson et al. 1994). The study found a limited doseresponse relationship between the three levels of the microbiologic index and variability in peak expiratory flow (flow decreases of 0.4 and $4.9 \%$ relative to the lowest category of the index), but little clear relationship for the two indices based on inspection for water damage.

Seuri (personal communication, July 24, 2002), in unpublished analyses of data from the abovementioned study (Seuri et al. 2000), found that the index based on moisture-indicating microorganisms and both the classification schemes based on visible water damage all were associated with some symptoms in the occupants. For instance, in comparing the best and worst groups on the three-level microbiologic index, ORs for cough ranged from 1.4-3.4, depending on which of three forms of symptom question was used, and for eye, nose, and throat symptoms ORs ranged from 1.0-1.7. The classifications based on inspection had associations with these symptoms of a similar magnitude.

Although sufficient data to compare the study buildings in the EPA BASE study and in the Finnish study (Seuri et al. 2000) are not available, it is highly likely that the Finnish study buildings, half of which were selected because of severe moisture and mold problems, would include more buildings at the highest levels of the moisture index than would a general building population such as in BASE. Thus fewer high exposure environments would be expected in the BASE data, and weaker associations of microbiologic metrics with health outcomes would be expected. Another important difference between the two studies is that all the Finnish buildings were studied in winter, so that moisture-indicating organisms indoors would be from indoor sources; however, half the EPA BASE buildings were studied in summer, so that AMIMOs from outdoor sources might have inflated the indoor concentrations although not attributable to indoor water damage. Thus the Finnish study would likely have contained substantially more buildings with true high AMIMO levels from indoor sources. Furthermore, many of the AMIMO metrics used here used an algorithm which assigned scores based on the total fungal concentrations in the BASE buildings, which would elevate scores for lower fungal concentrations here relative to those in the Finnish study (Macher et al. 2003).

Park et al. (2002) created and tested a semi-quantitative observational index of mold exposure for association with building-related symptoms in workers within 13 college office buildings. The index was based on room-specific classification of 7 areas (ceiling, walls, windows, floor, HVAC, heating/cooling pipes, and furniture) for water stains, visible mold, mold odor, and signs of moisture, each with a rating scale based on area or severity. This classification was combined with detailed personal information on time spent in each room location. Two versions of the index were created with differing weights for the different components. The authors reported significant exposure/response relationships between an exposure index based on visible water 
stains and wheeze, and between a combined exposure index and both chest tightness and shortness of breath. Other studies have also shown, although with less quantitative indicators of water damage, associations in non-residential buildings between water damage and respiratory health effects (Li et al. 1997; Wan and Li 1999; Savilahti et al. 2000; Jarvis and Morey 2001).

\section{Limitations of analysis}

This analysis did not fully replicate the analysis of Seuri et al. (2000) because of the difference mentioned above, and also for several other reasons: the BASE data contained similarly detailed microbiologic data, but more limited information on water damage; and the published study by Seuri assessed changes in lung function variability rather than the symptoms assessed in the BASE study, whereas the unpublished analyses by Seuri used different questionnaire formats than in the BASE study.

Although the AMIMO metrics in their original forms showed no overall pattern of association with either symptom outcome, nine (and especially four, i.e., those with concentration cutpoints $>100$ but $<500 \mathrm{CFU} / \mathrm{m}^{3}$ for total culturable fungi) of the 19 metrics did show associations when dichotomized based on the data. While this data-driven categorization may simply have capitalized upon a chance single association occurring among a handful of highly correlated metrics, this does not seem the most likely explanation of the findings, for the following reasons:

- The dichotomized AMIMO metrics were very strongly associated with variables for visible water damage, yet the AMIMO metrics had been dichotomized quite independently of their relation to water damage variables. This finding suggests that the dichotomous AMIMO metrics do measure a phenomenon highly correlated with water damage. Since water damage has been consistently associated with symptoms in many studies, this adds credibility to true AMIMO/symptom relationships.

- The pattern among the 19 metrics -generally increasing association with symptoms as the number of buildings in the highest category of the metric decreased (Table 3 ) - is consistent with a true relationship between the symptoms and a relatively rare high level of an underlying phenomenon at the high end of most of the metric scales. This is plausible, as the previously reported dose-response relationship for three levels of an AMIMO metric was in a building population half of which were selected because of severe water damage. Still, the findings here need replication with more explicit a priori predictions about performance of the metrics, to convincingly demonstrate the validity and usefulness of this approach.

\section{Recommendations}

Findings of this analysis did potentially corroborate the usefulness of the strategy used by Seuri and colleagues (2000) - using microorganisms to indicate moisture damage. It did not confirm the usefulness in general buildings of the specific metric they used. In the EPA BASE population of representative office buildings, metrics that ranked buildings by presence of moisture-indicating organisms and also contrasted the few highest-ranked buildings to all others generally produced the greatest contrasts in symptom risk (Table 3). Although our analysis did not fully explore this, this requirement may not be so stringent for AMIMO metrics in terms of 
association with visible water damage -even metrics with 6 buildings in the higher category had strong associations with water damage, although metrics with 8 buildings had fewer (Table 5). AMIMO metrics merit additional research and development for the prediction of water damage and of health effects - the latter may require different metrics. Inclusion of buildings with a greater range of both water damage and of health effects than in the BASE data may be necessary for this development. Inclusion of more objective measures of respiratory or other health outcomes, rather than only subjective symptoms, will also facilitate this research.

Research to validate and refine AMIMO metrics should also refine quantitative assessments of water damage in buildings. Ultimately, more refined AMIMO metrics, in conjunction with metrics for visible water damage such as reported by Park et al. (2002) seem to offer the most promise for quantifying health risks from water damage in buildings. Until the elusive causal exposures mediating the associations between moisture and health effects are identified, metrics for AMIMOs and visible water damage may provide the best available tools to study water damage and mold growth in buildings.

Findings here, on health effects correlated with indicators of water damage in buildings, supplement available findings that water damage is a risk for respiratory health effects (Bornehag et al. 2001). Although additional research is needed to clarify specific causal exposures, solutions are currently well understood. Preventive and remedial actions to reduce moisture and water damage in buildings continue to be advisable. 


\section{References}

Apte, M. G. and J. M. Daisey (1999). VOCs and sick building syndrome: application of a new statistical approach for SBS research to the US EPA BASE study data. Proceedings of Indoor Air '99: The 8th International Conference on Indoor Air Quality and Climate, Edinburgh, Scotland, Construction Research Communications Ltd. London.

Apte, M. G., W. J. Fisk, et al. (2000). "Associations between indoor CO2 concentrations and sick building syndrome symptoms in U.S. office buildings: an analysis of the 1994-1996 BASE study data." Indoor Air 10(4): 246-57.

Bornehag, C. G., G. Blomquist, et al. (2001). "Dampness in buildings and health: Nordic interdisciplinary review of the scientific evidence on associations between exposure to "dampness" in buildings and health effects (NORDDAMP)." Indoor Air 11(2): 72-86.

Brightman, H. S., L. A. Wallace, et al. (1999). Comparing symptoms in United States office buildings. Indoor Air '99: Proceedings of the 8th International Conference on Indoor Air Quality and Climate, Edinburgh, Scotland, Construction Research Communications Ltd.

Erdmann, C. A., K. C. Steiner, et al. (2002). Indoor carbon dioxide concentrations and sick building syndrome symptoms in the BASE study revisited: analyses of the 100 building dataset. Indoor Air '02: Proceedings of the 9th International Conference on Indoor Air Quality and Climate, Monterey, CA.

Haverinen, U., T. Husman, et al. (2001). "Comparison of two-level and three-level classifications of moisture-damaged dwellings in relation to health effects." Indoor Air 11(3): 192-199.

Jarvis, J. Q. and P. R. Morey (2001). "Allergic respiratory disease and fungal remediation in a building in a subtropical climate." Appl Occup Environ Hyg 16(3): 380-8.

Li, C. S., C. W. Hsu, et al. (1997). "Dampness and respiratory symptoms among workers in daycare centers in a subtropical climate." Arch Environ Health 52(1): 68-71.

Macher, J. M., M. J. Mendell, et al. (2003). Classification of U.S. EPA BASE buildings by indoor concentrations of airborne moisture-indicating micro-organisms (AMIMOs) and all airborne culturable fungi. Washington, D.C., U.S. Environmental Protection Agency: 25.

Mendell, M. J., M. Cozen, et al. (2003). Indicators of moisture and contamination in U.S. office buildings as risks for respiratory and irritant symptoms: analyses of the EPA BASE data, Lawrence Berkeley National Laboratory.

Park, J. H., P. L. Schleiff, et al. (2002). Semi-quantitative mold exposure index predicts buildingrelated respiratory symptoms. Indoor Air '02: Proceedings of the 9th International Conference on Indoor Air Quality and Climate, Monterey, CA, Indoor Air.

Samson, R. A., B. Flannigan, et al., Eds. (1994). Health implications of fungi in indoor environments. Air Quality Monographs.

SAS Institute Inc. (2002). SAS Version 8, http://www.sas.com/service/library/onlinedoc/. 2002.

Savilahti, R., J. Uitti, et al. (2000). "Respiratory morbidity among children following renovation of a water-damaged school." Archives of Environmental Health 55(6): 405-410.

Seuri, M., K. Lehtomaki, et al. (2000). Peak expiratory flow follow-up of workers employed in damp buildings. Healthy Buildings 2000: Exposure, Human Responses and Buildings Investigations, Espoo, Finland, SIY Indoor Air Information Oy, Helsinki, Finland.

Ten Brinke, J., S. Selvin, et al. (1998). "Development of new volatile organic compound (VOC) exposure metrics and their relationship to "sick building syndrome" symptoms." Indoor Air 8: 140-152. 
Wan, G. H. and C. S. Li (1999). "Dampness and airway inflammation and systemic symptoms in office building workers." Arch Environ Health 54(1): 58-63.

Womble, S. E., L. E. Burton, et al. (1999). Prevalence and concentrations of culturable airborne fungal spores in 86 office buildings from the Building Assessment Survey and Evaluation (BASE) study. Indoor Air '99: the 8th International Conference on Indoor Air Quality and Climate, Edinburgh, Scotland, Construction Research Communications Ltd.

Womble, S. E., E. L. Ronca, et al. (1996). Developing baseline information on buildings and indoor air quality (BASE '95). IAQ 96/Paths to Better Building Environments/Health Symptoms in Building Occupants, Atlanta, American Society of Heating Refrigeration and Air-conditioning Engineers. 
Table 1. Unadjusted ORs ${ }^{1}$ for associations between levels of 19 AMIMO metrics ${ }^{2}$ and symptom outcomes in 100 U.S. office buildings in the EPA BASE study, 1994-1998

\begin{tabular}{|c|c|c|c|c|c|c|c|c|c|c|c|c|c|c|c|c|c|c|c|c|c|}
\hline \multirow{2}{*}{\multicolumn{2}{|c|}{ AMIMO Metric }} & \multicolumn{10}{|c|}{$\begin{array}{c}\text { Weekly, work-related } \\
\text { lower respiratory symptoms }\end{array}$} & \multicolumn{10}{|c|}{$\begin{array}{c}\text { Weekly, work-related } \\
\text { mucous membrane symptoms }\end{array}$} \\
\hline & & \multicolumn{10}{|c|}{ AMIMO value } & \multicolumn{10}{|c|}{ AMIMO value } \\
\hline $\begin{array}{c}\text { Metric } \\
\text { number }\end{array}$ & $\begin{array}{c}\# \text { of } \\
\text { categories }\end{array}$ & $\mathbf{0}$ & 1 & 2 & 3 & 4 & 5 & 6 & 7 & 8 & 9 & $\mathbf{0}$ & 1 & 2 & 3 & 4 & 5 & 6 & 7 & 8 & 9 \\
\hline 1 & 3 & --- & 1.0 & 0.6 & 0.5 & --- & --- & --- & --- & --- & --- & --- & 1.0 & 0.9 & 0.8 & --- & --- & --- & --- & --- & --- \\
\hline 2 & 7 & --- & --- & --- & 1.0 & 0.8 & 0.6 & 0.5 & 0.6 & 0.5 & 0.5 & --- & --- & --- & 1.0 & 1.3 & 1.0 & 0.8 & 0.9 & 0.8 & 0.9 \\
\hline 3 & 10 & 1.0 & 1.3 & 0.9 & 1.8 & 0.9 & 0.9 & 0.7 & 1.1 & 1.0 & 1.0 & 1.0 & 1.1 & 1.1 & 1.7 & 1.0 & 0.9 & 1.0 & 1.1 & 1.0 & 1.1 \\
\hline 6 & 10 & 1.0 & 1.3 & 0.9 & 1.7 & 1.0 & 0.9 & 0.7 & 1.0 & 0.9 & 1.3 & 1.0 & 1.1 & 1.1 & 1.6 & 1.0 & 0.9 & 1.1 & 1.2 & 0.9 & 1.2 \\
\hline 7 & 4 & 1.0 & 0.7 & 0.8 & 0.7 & --- & --- & --- & --- & --- & --- & 1.0 & 0.9 & 0.8 & 0.9 & --- & --- & --- & --- & --- & --- \\
\hline 8 & 10 & 1.0 & 0.9 & 0.8 & 0.7 & 0.8 & 0.3 & 0.3 & 0.9 & 0.8 & 1.0 & 1.0 & 0.9 & 0.8 & 0.8 & 0.8 & 0.6 & 0.9 & 1.0 & 0.8 & 1.0 \\
\hline 9 & 4 & 1.0 & 0.8 & 0.4 & 0.9 & --- & --- & --- & --- & --- & --- & 1.0 & 1.0 & 0.6 & 1.0 & --- & --- & --- & --- & --- & --- \\
\hline 10 & 10 & 1.0 & 0.9 & 0.8 & 0.7 & 0.9 & 0.3 & 0.2 & 0.9 & 0.8 & 1.3 & 1.0 & 0.9 & 0.8 & 0.8 & 0.8 & 0.6 & 0.8 & 1.0 & 0.8 & 1.2 \\
\hline 15 & 4 & 1.0 & 0.9 & 0.9 & 0.9 & --- & --- & --- & --- & --- & --- & 1.0 & 0.1 & 0.8 & 1.0 & --- & --- & --- & --- & --- & --- \\
\hline 16 & 10 & 1.0 & 0.9 & 0.7 & 0.7 & 1.0 & 0.6 & 0.5 & 0.9 & 1.2 & 1.2 & 1.0 & 0.9 & 0.8 & 0.8 & 1.0 & 0.7 & 0.7 & 1.0 & 0.8 & 1.4 \\
\hline 17 & 4 & 1.0 & 0.9 & 0.8 & 1.0 & --- & --- & --- & --- & --- & --- & 1.0 & 1.1 & 0.8 & 1.1 & --- & --- & --- & --- & --- & --- \\
\hline 18 & 10 & 1.0 & 0.9 & 0.7 & 0.7 & 0.8 & 0.7 & 1.1 & 0.9 & --- & 1.0 & 1.0 & 0.9 & 0.8 & 0.9 & 1.0 & 0.7 & 1.0 & 1.0 & $--^{3}$ & 1.0 \\
\hline 19 & 4 & 1.0 & 0.8 & 0.8 & 1.2 & --- & --- & --- & --- & --- & --- & 1.0 & 1.0 & 0.8 & 1.1 & --- & --- & --- & --- & --- & --- \\
\hline
\end{tabular}

Confidence interval for all ORs in table include 1.0.

2 Scales for AMIMO metrics varied in their range; dashes (---) indicate cells outside range of the metric

${ }^{3}$ no buildings at this level of metric 
Table 2. Adjusted ${ }^{1}$ ORs for associations between levels of 19 AMIMO metrics ${ }^{2}$ and symptom outcomes in 100 U.S. office buildings in the EPA BASE study, 1994-1998

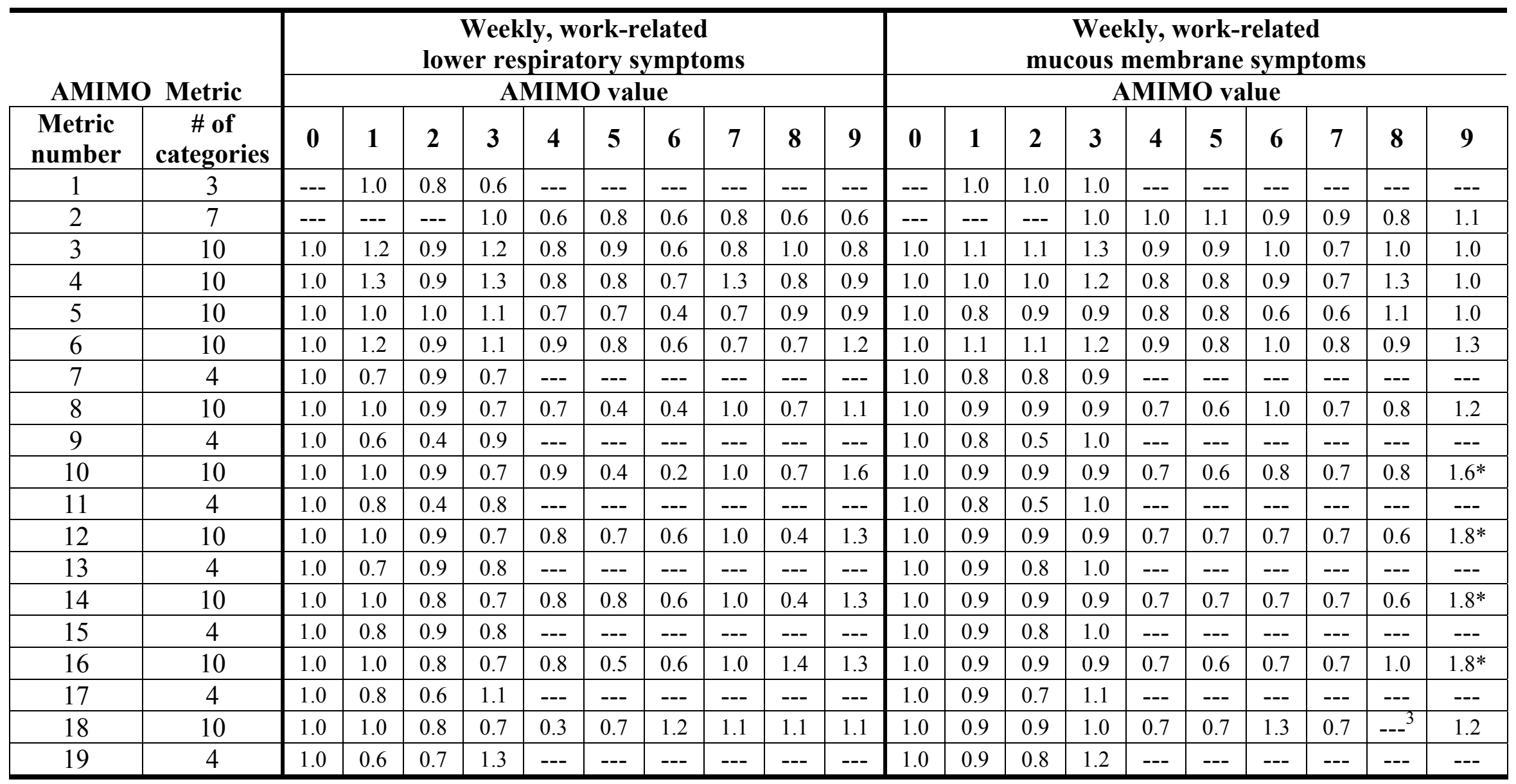

* $95 \%$ confidence interval excludes 1.0

1 Each model potentially adjusted for personal variables (gender, age, job, education, smoking, asthma, mold allergy, hayfever, computer use, photocopier use, work hours per week, years working in building, job satisfaction, job demand, job conflict) and ventilation and thermal parameters (temperature, relative humidity, ventilation rate, heating and cooling degree days).

${ }^{2}$ Scales for AMIMO metrics varied in their range; dashes (---) indicate cells outside range of the metric 
AMIMO Tables 3-5 rev 9-11-03

${ }^{3}$ no buildings at this level of metric 
Table 3. Unadjusted and adjusted ${ }^{1}$ ORs (95\% CIs) for associations between 19 dichotomized AMIMO metrics and weekly, work-related symptom outcomes, ordered by decreasing numbers of buildings in higher category, in 100 U.S. office buildings in the EPA BASE study, 1994-1998

\begin{tabular}{|c|c|c|c|c|c|c|}
\hline \multirow[b]{2}{*}{$\begin{array}{l}\text { AMIMO } \\
\text { Metric }^{2}\end{array}$} & \multirow[b]{2}{*}{$\begin{array}{c}\text { Number of } \\
\text { categories } \\
\text { in original } \\
\text { metric }\end{array}$} & \multirow[b]{2}{*}{$\begin{array}{l}\text { Number of } \\
\text { buildings, } \\
\text { of } 100, \\
\text { in highest } \\
\text { original } \\
\text { AMIMO } \\
\text { category }\end{array}$} & \multicolumn{2}{|c|}{ Unadjusted Outcomes } & \multicolumn{2}{|c|}{ Adjusted ${ }^{1}$ Outcomes } \\
\hline & & & $\begin{array}{l}\text { Weekly, work- } \\
\text { related lower } \\
\text { respiratory } \\
\text { symptoms } \\
\text { OR }(95 \% \mathrm{CI})\end{array}$ & $\begin{array}{l}\text { Weekly, work- } \\
\text { related mucous } \\
\text { membrane } \\
\text { symptoms } \\
\text { OR }(95 \% \mathrm{CI})\end{array}$ & $\begin{array}{l}\text { Weekly, work- } \\
\text { related lower } \\
\text { respiratory } \\
\text { symptoms } \\
\text { OR }(95 \% \mathrm{CI})\end{array}$ & $\begin{array}{l}\text { Weekly, work- } \\
\text { related mucous } \\
\text { membrane } \\
\text { symptoms } \\
\text { OR }(95 \% \mathrm{CI})\end{array}$ \\
\hline 1 & 3 & 32 & $0.9(0.7-1.1)$ & $1.0(0.8-1.1)$ & $0.8(0.6-1.1)$ & $1.0(0.9-1.2)$ \\
\hline 7 & 4 & 21 & $0.8(0.6-1.1)$ & $0.9(0.8-1.1)$ & $0.8(0.6-1.1)$ & $1.0(0.8-1.2)$ \\
\hline 2 & 7 & 17 & $0.9(0.7-1.2)$ & $1.0(0.8-1.2)$ & $0.9(0.6-1.3)$ & $1.1(0.9-1.4)$ \\
\hline 9 & 4 & 13 & $0.9(0.7-1.3)$ & $1.0(0.8-1.2)$ & $0.9(0.6-1.3)$ & $1.1(0.8-1.3)$ \\
\hline 11 & 4 & 13 & $0.9(0.7-1.3)$ & $1.0(0.8-1.2)$ & $0.9(0.6-1.3)$ & $1.1(0.8-1.3)$ \\
\hline 13 & 4 & 9 & $0.9(0.6-1.3)$ & $1.0(0.8-1.3)$ & $0.9(0.6-1.3)$ & $1.0(0.8-1.3)$ \\
\hline 15 & 4 & 9 & $0.9(0.6-1.3)$ & $1.0(0.8-1.3)$ & $0.9(0.6-1.3)$ & $1.0(0.8-1.3)$ \\
\hline 3 & 10 & 9 & $0.9(0.6-1.3)$ & $1.0(0.8-1.3)$ & $0.9(0.6-1.3)$ & $1.0(0.8-1.3)$ \\
\hline 4 & 10 & 9 & $0.9(0.6-1.3)$ & $1.0(0.8-1.3)$ & $0.9(0.6-1.3)$ & $1.0(0.8-1.3)$ \\
\hline 17 & 4 & 8 & $1.0(0.7-1.6)$ & $1.1(0.9-1.4)$ & $1.2(0.8-1.9)$ & $1.2(0.9-1.6)$ \\
\hline 19 & 4 & 6 & $1.2(0.8-2.0)$ & $1.2(0.9-1.5)$ & $1.3(0.8-2.2)$ & $1.2(0.9-1.7)$ \\
\hline 5 & 10 & 6 & $1.0(0.6-1.6)$ & $1.1(0.9-1.5)$ & $1.1(0.6-1.8)$ & $1.3(0.9-1.7)$ \\
\hline 6 & 10 & 5 & $1.2(0.7-2.0)$ & $1.1(0.8-1.6)$ & $1.3(0.8-2.2)$ & $1.3(0.9-1.9)$ \\
\hline 8 & 10 & 5 & $1.2(0.7-2.0)$ & $1.1(0.8-1.6)$ & $1.3(0.8-2.2)$ & $1.3(0.9-1.9)$ \\
\hline 10 & 10 & 4 & $1.6(1.0-2.7)$ & $1.4(1.0-1.9)$ & $1.9 *(1.1-3.2)$ & $1.8 *(1.2-2.7)$ \\
\hline 12 & 10 & 3 & $1.5(0.8-2.7)$ & $1.6^{*}(1.1-2.4)$ & $1.7(0.9-3.2)$ & $2.1 *(1.4-3.3)$ \\
\hline 14 & 10 & 3 & $1.5(0.8-2.7)$ & $1.6^{*}(1.1-2.4)$ & $1.7(0.9-3.2)$ & $2.1 *(1.4-3.3)$ \\
\hline 16 & 10 & 3 & $1.5(0.8-2.7)$ & $1.6^{*}(1.1-2.4)$ & $1.7(0.9-3.2)$ & $2.1 *(1.4-3.3)$ \\
\hline 18 & 10 & 1 & $1.1(0.3-3.6)$ & $1.1(0.5-2.3)$ & $1.3(0.4-4.3)$ & $1.2(0.6-2.7)$ \\
\hline
\end{tabular}

1 potentially adjusted for personal variables, and ventilation and thermal parameters included in Table 2 , footnote 1 .

2 dichotomous metrics comparing buildings in the highest single original category of the metric to buildings from all lower categories combined. 
Table 4. Adjusted ${ }^{1}$ associations between weekly, work-related symptoms and summary variables for water damage in study spaces and buildings, from the EPA BASE data collected from U.S. office buildings, 1994-1998

\begin{tabular}{ccc} 
& $\begin{array}{c}\text { Weekly work- } \\
\text { Covariates }\end{array}$ & $\begin{array}{c}\text { Weekly work- } \\
\text { related lower } \\
\text { related mucous }\end{array}$ \\
(BASE data variable name) & symptoms & membrane \\
& ORymptoms \\
& OR $(95 \% \mathrm{CI})$ & OR $(95 \% \mathrm{CI})$ \\
\hline
\end{tabular}

Specific water damage variables

CURRENT STUDY SPACE

CURRENT

BUILDING

(N)
Current water damage, basement (A2H2O2A)
Current water damage, roof (A2H2O2B)

PAST Past water damage, STUDY SPACE study space (B2H2O1D)

Past water damage, study mechanical room (B2H2O1C)

PAST Past water damage, any

BUILDING

Summary water damage variables

study space (B2H2O2D)

urrent water damage, study

mechanical room (B2H2O2C)

mechanical room (A2H2O1C)

Past water damage, basement (A2H2O1A)

Past water damage, roof (A2H2O1B)

Past fire damage in building (A2FIRE)
$1.2(0.8-1.9)$

$0.9(0.6-1.3)$

damage in study space

Any current water

damage in building

$0.8(0.6-1.2) \quad 1.0(0.8-1.3)$

Any past water

damage in study space

$1.0(0.7-1.4) \quad 1.2(1.0-1.6)$

Any past water

damage in building

$1.3(0.9-1.8) \quad 1.1(0.9-1.5)$

* p-value less than 0.05

1 Each model potentially adjusted for personal variables (gender, age, job, education, smoking, asthma, mold allergy, hayfever, computer use, photocopier use, work hours per week, years working in building, job satisfaction, job demand, job conflict); HVAC condition and 
maintenance (frequency of coil and pan cleaning, filter condition, filter change frequency, filter fit, mechanical room condition, cooling coil condition, duct liner condition); HVAC design and materials (supply duct surface material, particle filter efficiency, air intake near cooling tower); study space cleaning (vacuuming frequency, wet mopping frequency, dry mopping frequency); and ventilation and thermal parameters (temperature, relative humidity, ventilation rate, heating and cooling degree days). 
Table 5. ORs (95\% CIs) for unadjusted associations $(\mathrm{p} \leq \mathbf{0 . 2 5})$ between known water damage and selected dichotomized AMIMO metrics, from the EPA BASE data collected from U.S. office buildings, 1994-1998

\begin{tabular}{|c|c|c|c|c|c|c|c|c|}
\hline \multirow{3}{*}{ Covariates } & \multirow{3}{*}{$\begin{array}{c}\text { Proportion } \\
\text { of buildings } \\
\% \\
\text { (variable name) }\end{array}$} & \multicolumn{7}{|c|}{$\begin{array}{c}\text { AMIMO Metric \# } \\
\text { (number of buildings in higher category) }\end{array}$} \\
\hline & & $\begin{array}{c}18 \\
\text { (1 bldg) }\end{array}$ & $\begin{array}{l}12,14,16 \\
(3 \text { bldgs })\end{array}$ & $\begin{array}{c}10 \\
(4 \text { bldgs })\end{array}$ & $\begin{array}{c}6,8 \\
(5 \text { bldgs })\end{array}$ & $\begin{array}{c}19 \\
\text { (6 bldgs) }\end{array}$ & $\begin{array}{c}5 \\
(6 \text { bldgs })\end{array}$ & $\begin{array}{c}17 \\
\text { (8 bldgs) }\end{array}$ \\
\hline & & & $\begin{array}{c}\text { OR } \\
(95 \% \mathrm{CI}) \\
\end{array}$ & $\begin{array}{c}\mathrm{OR} \\
(95 \% \mathrm{CI}) \\
\end{array}$ & $\begin{array}{c}\mathrm{OR} \\
(95 \% \mathrm{CI}) \\
\end{array}$ & $\begin{array}{c}\mathrm{OR} \\
(95 \% \mathrm{CI}) \\
\end{array}$ & $\begin{array}{c}\mathrm{OR} \\
(95 \% \mathrm{CI}) \\
\end{array}$ & $\begin{array}{c}\mathrm{OR} \\
(95 \% \mathrm{CI}) \\
\end{array}$ \\
\hline \multicolumn{9}{|l|}{$\begin{array}{l}\text { Specific water damage } \\
\text { variables }\end{array}$} \\
\hline $\begin{array}{l}\text { Current water damage, } \\
\text { study space }\end{array}$ & $\begin{array}{c}14 \\
(\mathrm{~B} 2 \mathrm{H} 2 \mathrm{O} 2 \mathrm{D})\end{array}$ & --- & $\begin{array}{c}3.2 \\
(0.3-38.2)\end{array}$ & $\begin{array}{c}2.1 \\
(0.2-22.0)\end{array}$ & $\begin{array}{c}1.6 \\
(0.2-15.2)\end{array}$ & $\begin{array}{c}1.2 \\
(0.1-11.5)\end{array}$ & $\begin{array}{c}3.4 \\
(0.6-20.7)\end{array}$ & $\begin{array}{c}2.2 \\
(0.4-12.3)\end{array}$ \\
\hline $\begin{array}{l}\text { Current water damage, } \\
\text { study mechanical } \\
\text { room }\end{array}$ & $\begin{array}{c}3 \\
(\mathrm{~B} 2 \mathrm{H} 2 \mathrm{O} 2 \mathrm{C})\end{array}$ & --- & --- & $\begin{array}{c}15.7 * \\
(1.1-224)\end{array}$ & $\begin{array}{c}11.6 \\
(0.9-157)\end{array}$ & $\begin{array}{c}9.2 \\
(0.7-119)\end{array}$ & $\begin{array}{c}9.2 \\
(0.7-119)\end{array}$ & $\begin{array}{c}6.4 \\
(0.5-80.0)\end{array}$ \\
\hline $\begin{array}{l}\text { Current water damage, } \\
\text { basement }\end{array}$ & $\begin{array}{c}13 \\
(\mathrm{~A} 2 \mathrm{H} 2 \mathrm{O} 2 \mathrm{~A})\end{array}$ & --- & $\begin{array}{c}15.6^{*} \\
(1.3-187)\end{array}$ & $\begin{array}{c}7.7 \\
(1.0-60.5)\end{array}$ & $\begin{array}{c}5.1 \\
(0.8-33.9)\end{array}$ & $\begin{array}{c}3.8 \\
(0.6-23.1)\end{array}$ & $\begin{array}{c}3.8 \\
(0.6-23.1)\end{array}$ & $\begin{array}{c}2.5 \\
(0.4-13.7)\end{array}$ \\
\hline $\begin{array}{l}\text { Past water damage, } \\
\text { study space }\end{array}$ & $\begin{array}{c}32 \\
(\mathrm{~B} 2 \mathrm{H} 2 \mathrm{O} 1 \mathrm{D})\end{array}$ & --- & $\begin{array}{c}4.5 \\
(0.4-51.2)\end{array}$ & $\begin{array}{c}6.9 \\
(0.7-69.5)\end{array}$ & $\begin{array}{c}9.6^{*} \\
(1.0-89.5)\end{array}$ & $\begin{array}{c}4.7 \\
(0.8-27.2)\end{array}$ & $\begin{array}{c}12.4^{*} \\
(1.4-111)\end{array}$ & $\begin{array}{c}4.0 \\
(0.9-18.0)\end{array}$ \\
\hline $\begin{array}{l}\text { Past water damage, } \\
\text { basement }\end{array}$ & $\begin{array}{c}28 \\
(\mathrm{~A} 2 \mathrm{H} 2 \mathrm{O} 1 \mathrm{~A})\end{array}$ & --- & --- & $\begin{array}{c}8.5 \\
(0.8-85.7)\end{array}$ & $\begin{array}{c}11.8^{*} \\
(1.3-111)\end{array}$ & $\begin{array}{c}5.8^{*} \\
(1.0-33.9)\end{array}$ & $\begin{array}{c}5.8^{*} \\
(1.0-33.9)\end{array}$ & $\begin{array}{c}5.0^{*} \\
(1.1-22.6)\end{array}$ \\
\hline $\begin{array}{l}\text { Past fire damage in } \\
\text { building }\end{array}$ & $\begin{array}{c}12 \\
(\mathrm{~A} 2 \mathrm{FIRE})\end{array}$ & --- & $\begin{array}{c}17.4^{*} \\
(1.4-209)\end{array}$ & $\begin{array}{c}8.6^{*} \\
(1.1-67.9)\end{array}$ & $\begin{array}{c}5.7 \\
(0.8-38.1)\end{array}$ & $\begin{array}{c}4.2 \\
(0.7-25.9)\end{array}$ & $\begin{array}{c}4.2 \\
(0.7-25.9)\end{array}$ & $\begin{array}{c}2.7 \\
(0.5-15.4)\end{array}$ \\
\hline \multicolumn{9}{|l|}{$\begin{array}{l}\text { Summary water damage } \\
\text { variables }\end{array}$} \\
\hline $\begin{array}{l}\text { Any current water } \\
\text { damage in study } \\
\text { space }\end{array}$ & $\begin{array}{c}16 \\
\text { (CURRWTRTS) }\end{array}$ & --- & $\begin{array}{c}2.7 \\
(0.2-32.1)\end{array}$ & $\begin{array}{c}5.8 \\
(0.8-45.1)\end{array}$ & $\begin{array}{c}3.9 \\
(0.6-25.2)\end{array}$ & $\begin{array}{c}2.9 \\
(0.5-17.1)\end{array}$ & $\begin{array}{c}6.2 * \\
(1.1-34.2)\end{array}$ & $\begin{array}{c}3.6 \\
(0.8-17.1)\end{array}$ \\
\hline $\begin{array}{l}\text { Any current water } \\
\text { damage in building }\end{array}$ & $\begin{array}{c}28 \\
(\text { CURRWTRB) }\end{array}$ & --- & $\begin{array}{c}5.5 \\
(0.5-62.8)\end{array}$ & $\begin{array}{c}2.7 \\
(0.4-20.1)\end{array}$ & $\begin{array}{c}1.8 \\
(0.3-11.2)\end{array}$ & $\begin{array}{c}1.3 \\
(0.2-7.6)\end{array}$ & $\begin{array}{c}1.3 \\
(0.2-7.6)\end{array}$ & $\begin{array}{c}1.6 \\
(0.4-7.2)\end{array}$ \\
\hline $\begin{array}{l}\text { Any past water } \\
\text { damage in study space }\end{array}$ & $\begin{array}{c}35 \\
\text { (PSTWTRTS) }\end{array}$ & --- & $\begin{array}{c}3.9 \\
(0.3-44.4)\end{array}$ & $\begin{array}{c}6.0 \\
(06-60.0)\end{array}$ & $\begin{array}{c}8.3 \\
(0.9-77.0)\end{array}$ & $\begin{array}{c}4.1 \\
(0.7-23.4)\end{array}$ & $\begin{array}{c}10.7^{*} \\
(1.2-95.3)\end{array}$ & $\begin{array}{c}3.4 \\
(0.8-15.4)\end{array}$ \\
\hline
\end{tabular}

